University of Wollongong

Research Online

Faculty of Engineering - Papers (Archive)

Faculty of Engineering and Information

Sciences

$1-1-2012$

\title{
Microstructural characterisation of railhead damage in insulated rail joints
}

C Rathod

University of Wollongong, crr716@uowmail.edu.au

David Wexler

University of Wollongong, david_wexler@uow.edu.au

Tara Chandra

University of Wollongong, tara@uow.edu.au

Huijun Li

University of Wollongong, huijun@uow.edu.au

Follow this and additional works at: https://ro.uow.edu.au/engpapers

Part of the Engineering Commons

https://ro.uow.edu.au/engpapers/5321

\section{Recommended Citation}

Rathod, C; Wexler, David; Chandra, Tara; and Li, Huijun: Microstructural characterisation of railhead damage in insulated rail joints 2012, 2937-2942.

https://ro.uow.edu.au/engpapers/5321

Research Online is the open access institutional repository for the University of Wollongong. For further information contact the UOW Library: research-pubs@uow.edu.au 


\title{
Microstructural characterisation of railhead damage in insulated rail joints
}

\author{
C.Rathod ${ }^{1 \mathrm{a}}$, D.Wexler ${ }^{1 \mathrm{~b}}, \mathrm{~T}$. Chandra ${ }^{1 \mathrm{c}}$ and H. Li ${ }^{1 \mathrm{~d}}$ \\ ${ }^{1}$ Faculty of Engineering, University of Wollongong, Northfields Ave, Wollongong Australia 2522 \\ acrr716@uowmail.edu.au, bdavidw@uow.edu.au, ct.chandra@uow.edu.au, dhuijun_Li@uow.edu.au
}

Keywords: Insulated rail joints, rail, head hardened, surface coated rail

\begin{abstract}
As an integral part the railway network infrastructure, insulated rail joints (IRJs) electrically isolate track segments providing critical feedback to both track signaling and train position detection systems. Because of the discontinuous nature of IRJs, accumulated damage at the railhead is high. Failure modes include plastic flow of metal across joints, bolt and fishplate failures, delamination of insulated material and, as a result of rolling contact fatigue, end post and endpost surface damage. In the current investigation, microstructural changes in the vicinity of endposts of IRJs made from both surface coated and uncoated rail are investigated using techniques of optical and scanning electron microscopy. Damaged IRJs made from pearlitic head hardened rail steel are compared with head hardened rail steel laser coated with martensitic stainless steel, the latter having an increased service life. Problems associated with the surface coating are identified and approaches to further improving IRJ resistance to rolling contact fatigue suggested.
\end{abstract}

\section{Introduction and Background}

Insulated Rail Joints (IRJs) play a key role in signaling systems in rail networks. End-to-end track sections are separated by a short insulating gap, often called an end post, while rigidity of IRJ components is obtained by bolted side joint bars, called fishplates, which are also electrically isolated from the track by a layer of composite resin [1, 2] (Fig. 1).

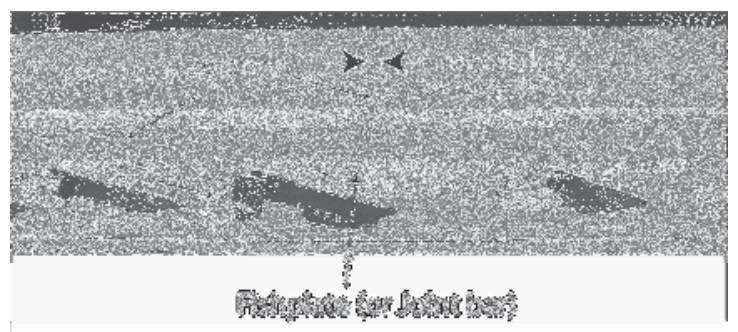

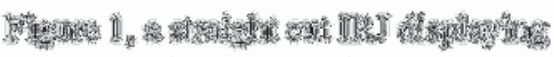
कीh

IRJ assemblies enable electrical isolation of track sections so that an electrical signal passing through a train's wheels can be used for a variety of functions including signaling the train's position and activate initiate of events such as the closing of level crossing boom gates. IRJs also play a secondary role as an aid to the detection of rail fractures in track segments. However, as one of the weakest components of the rail track systems [3], IRJ's pose a significant impact on maintenance costs due to their low and fluctuating service lives compared to continuously welded rail sections. The poor service reliability of IRJs is a particular problem in heavy haul rail corridors. Within Australia, 4-bolt and 6-bolt joint bars are the two most common IRJ assembly designs. The fishplate/bolt assemblies insulation is achieved by plastic liners for the fishplate, or by fully insulated fishplate encased by plastic liners/phenolic resins or/and by glued joints covered with epoxy resin/polyester and are subsequently welded into the track of desired short rail length. 
A majority of IRJ failures in Australian heavy haul rail corridors are caused by flow of steel over the rail end-posts [4] High impact forces cause rail damage such as spalling, squashing, and saddle backed wear [5]. Deterioration of the integrity of the bolt, fishplate, epoxy bonding and support configurations, which themselves experience combined lateral and vertical bending stresses, leads to a vicious circle accelerating the failure at the joint [6-8]. Failure itself is generally characterised by either an unsafe gap or other evidence of defects which might result in catastrophic failure. Grinding out the track surface can mitigate problems associated with metal flow over the gap [910]. However, eventually the IRJ assembly must be replaced. This involves cutting out of a section of track, around 1.5-2.5 m in length, and rewelding a new length of track containing the new IRJ.

Various approaches have been employed to increase the lifetimes of IRJs. These include; decreasing the gap size, from 7-8 $\mathrm{mm}$ to around 5-6 $\mathrm{mm}$, which results in less impact on rail ends; experimentation with the suspension and support configuration to give high deflections and lower impact loads [11, 12]; and altering the length of the joint bars according to whether they are 4-bolt or 6-bolt joints [13]. One to reducing the wheel-rail impact over joints has been to change from straight/conventional IRJs to 15 degree tapered cut IRJs (Fig. 2(a)). However, even after changing to tapered cut joint, metal flow at the surface was not completely eliminated [14]. A recent approach has involved use of a surface coating applied at the railhead with a hard tough material with high hardness, higher yield stress limit than the rail steel. It is expected that higher hardness and toughness of the rail might reduce the extent of rail-end flow leading to reducing maintenance and replacement.

As part of our effort to increase understanding of relationships between IRJ design and lifetime we compared degradation mechanisms in two different angled cut IRJs, one made from head hardened rail and deemed to be a failed joint due to metal flow, and second, a coated joint removed from service after the same period of operation under heavy haul rail traffic. Hereafter, the uncoated rail and grade 431 martensitic stainless steel laser coated rail will be designated as Rail U and Rail C respectively.

\section{Experimental}

Both the coated and uncoated angle cut, 6-bolt, IRJs were fabricated from Australian standard 60g grade head hardened steel AS 1085.12 with composition as listed in Table 1.

Table 1: Chemical Composition of Rail Steels.

\begin{tabular}{|c|c|c|c|c|c|c|c|c|c|c|c|}
\hline Element & $\mathrm{C}$ & $\mathrm{P}$ & $\mathrm{Mn}$ & $\mathrm{Si}$ & $\mathrm{S}$ & $\mathrm{Ni}$ & $\mathrm{Cr}$ & $\mathrm{Mo}$ & $\mathrm{Cu}$ & $\mathrm{Al}$ & $\mathrm{Sn}$ \\
\hline $\mathrm{W} \mathrm{t} \%$ & 0.64 & 0.031 & 0.75 & 0.15 & 0.027 & 0.024 & 0.062 & $<0.002$ & 0.041 & 0.003 & 0.003 \\
\hline
\end{tabular}

The test piece for surface coating with MSS was prepared by machining a "bathtub" shape into the head of the rail and then powder laser depositing of a 431 Martensitic Stainless Steel (MSS), as shown in Fig 2. Laser deposition has chosen over other deposition technique because of the finer microstructure and smaller heat affected zones compared to that resulting from deposition techniques such as hard facing by stick weld deposition. Full details are of the deposition methodology are commercial-in-confidence.

Macro optical imaging and both optical and scanning electron microscopies were used as the principal analytical techniques for this investigation. Specimens of rail head in the vicinity of the rail ends were sectioned in transverse and longitudinal directions to the long axis of the rail. Macro images were obtained from separated rail ends with no cleaning or chemical treatment. Samples 
prepared for microscopy and hardness testing were ground and polished to a $1 \mu \mathrm{m}$ finish and etched with $2 \%$ nital solution and $10 \%$ oxalic acid. A Leica DMRM was used for optical microscopy. Microhardness in transverse section was performed using LECO M-400-H1 Hardness machine at 500 gram load. Hardness values associated with a particular region were taken as an average of 8-10 readings. A JEOL JSM-6490LA model scanning electron microscope equipped with JEOL X-ray energy dispersive analysis system was used for secondary electron and backscattered electron SEM imaging.

(a)
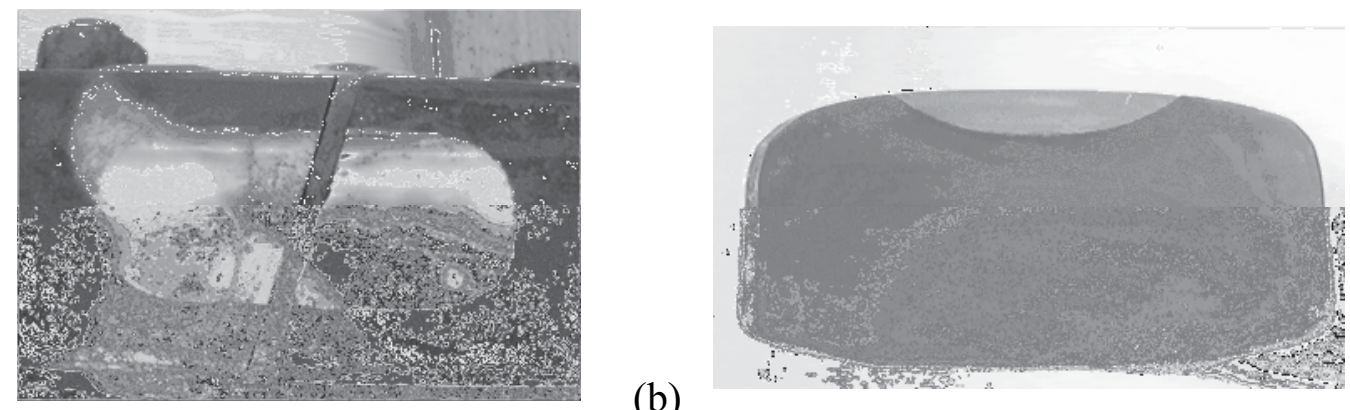

Figure 2 Martensitic stainless steel IRJ, (a) top view of ex-service IRJ fabricated with a 15 degree angle cut, (b) section showing bathtub shape of metal deposit,.

\section{Results and Discussion}

\section{Uncoated rail (Rail U)}

The rail ends of the failed uncoated joint showed severe deformation in the head hardened region, near the top rail surface, with microstructural evidence of both metal flow over the rail ends metal fracture, and in-service related fatigue mechanisms consistent with rolling contact fatigue [11]. Macro metallographic results obtained from one rail end are described in Fig 3, which includes (a) side-on and (b) top views of the damage rail end. The direction of travel of the rail traffic was in the direction of the metal flow. Top surface cracks in the feature protruding around $2 \mathrm{~mm}$ over the rail end are revealed in Fig 3(c) and the whole feature was easily removed from the rail head ((compare Fig 3(c) and 3(d)).

Collected evidence suggests strongly that sub-surface-initiated cracks are propagated by a rolling contact fatigue mechanism that has led to spalling of the hard surface of the head hardened. Beach/striation marks are evident on the fracture surface (Fig 3(e)) which is attributed by the repeated rolling-sliding contact loading. Due to uniformity of loading beach marks are fairly similarly spaced and fairly uniform in appearance. Fatigue failures occur due to high cyclic loading which initiates the crack and propagates until a stress much lower than that necessary to cause a fracture [12]. The region inside the oval box contains the initial beach marks (the smallest elliptical features) and this is believed to be where the cracking has initiated. SEM-EDS investigations of regions below the rail surface (not shown) revealed inclusions including MnS which are likely sites for crack initiation.

\section{Uncoated rail (Rail U)}

Damage to the IRJ ends of the stainless coated samples (Fig 4) was significantly different to that of the head hardened rail. Plastic deformation over the top surface of the centre of the rail was less, consistent with expected mechanical property advantages of martensitic stainless steel over medium carbon rail steel (hardness, toughness, flow stress). However, there was notable plastic deformation 
in the coated sample in the vicinity of the interfaces between the rail steel and coating near at the top surface of the coating (Fig 4(a) - (c)). This, in part, could be related to mismatches in metal flow, being greater for the rail steel than for the stainless steel. The type of cracking differed on each side of the track, with more oblique crack growth (Fig 4(c)) on the gauge (wheel) side (wheel side) than near the field side. One approach to mitigating the problems near the top rail surfaces might be via re-design of the shape of the coating profile. The shallow angle of between the stainless steel-rail steel interface and the top surface of the rail ( $<30$ degrees) could be changed to a much steeper angle (near 90 degrees) to reduce the component of shear stresses acting on the interface.
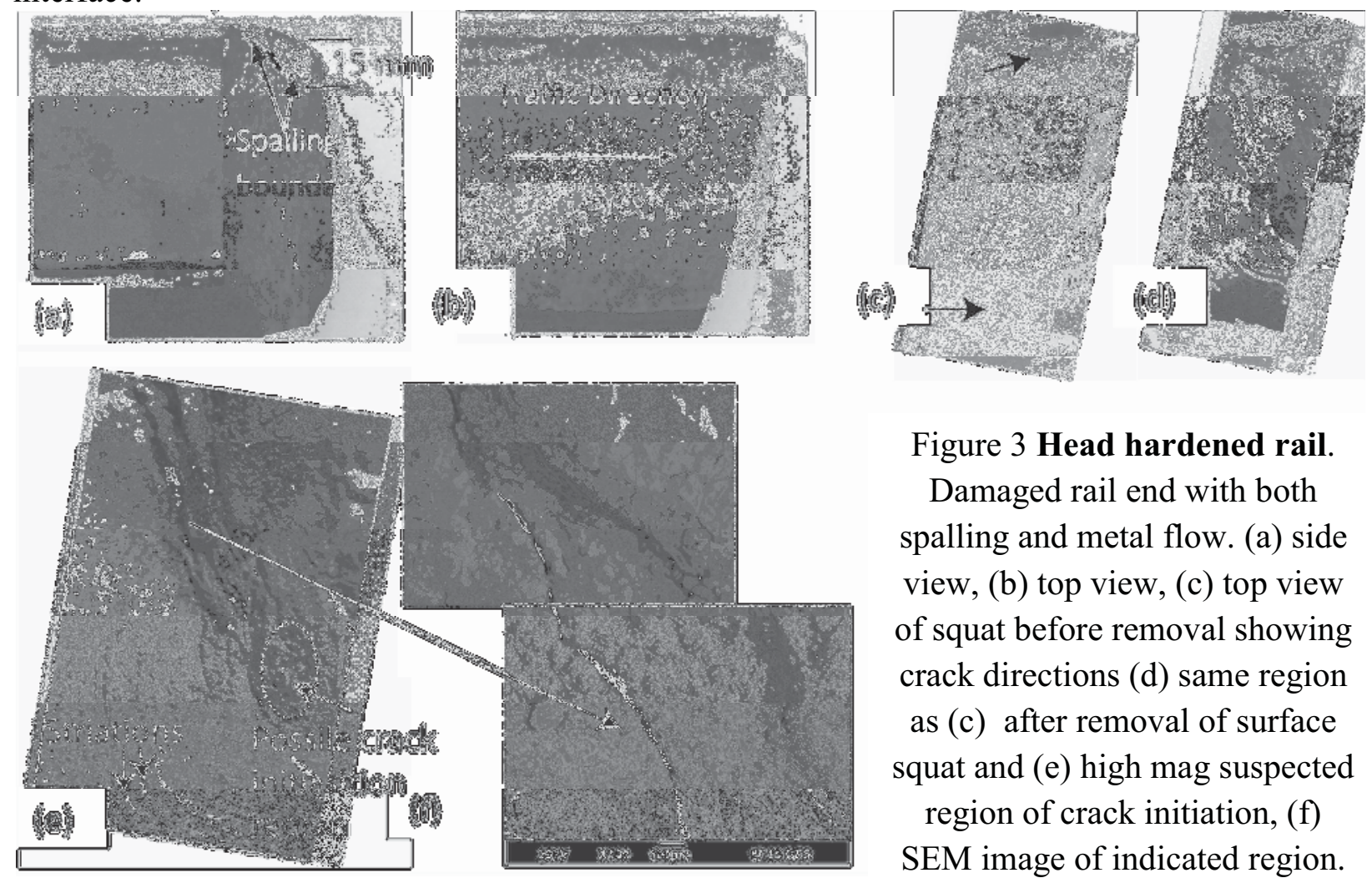

Figure 3 Head hardened rail.

Damaged rail end with both spalling and metal flow. (a) side view, (b) top view, (c) top view of squat before removal showing crack directions (d) same region as (c) after removal of surface squat and (e) high mag suspected region of crack initiation, (f) SEM image of indicated region.

Examination of both transverse sections (Fig 4(d)) and longitudinal sections (not shown) located well below the top rail surface revealed cracks originating in regions of weld porosity and defects in the vicinity of interface between the rail steel and the coating (Fig 4(d) and SEM image, Fig 4(e)). Cracks associated with inclusions in the rail steel and in regions in the vicinity of the stainless steelrail steel interface were also observed but are not shown. It is expected that complex residual stresses originating from the mismatches in thermal expansion coefficient of the two different types of steel contribute to the problem of interface cracking, crack initiation and crack growth both before and during service life. Based on these results, apart from void formation, major issues to deal with during the initial laser cladding process include the management of defects initiated in the heat affected zone of the rail steel and the formation of $\mathrm{Cr}$ rich precipitates on the interface.

Transverse cross-sections of the head hardened rail and weld inlay rail samples were examined with data obtained from the rail surfaces going down into the rail head. For a position around $10 \mathrm{~cm}$ back from the rail end the uncoated head hardened rail had mean microhardnesses of; $430 \mathrm{HV}(500 \mathrm{~g})$, $350 \mathrm{HV}(500 \mathrm{~g}), 267 \mathrm{HV}(500 \mathrm{~g}) 1 \mathrm{~mm}$ below the top surface, in the subsurface, and in a regions below the head hardened surface, respectively. There were in accordance with typical values for this grade of head hardened rail. Trends in microhardness profiles close to the top surfaces of both samples, from the centre of railhead to a depth, of $10 \mathrm{~mm}$, are shown in Fig. 5. Factors contributing to these results include; (i) the higher hardness of the martensitic stainless steel over the rail steel, (ii) changes in head hardness of the head hardened steel as a function of depth and (iii) surface strain hardening effects associated with deformation during service life. 

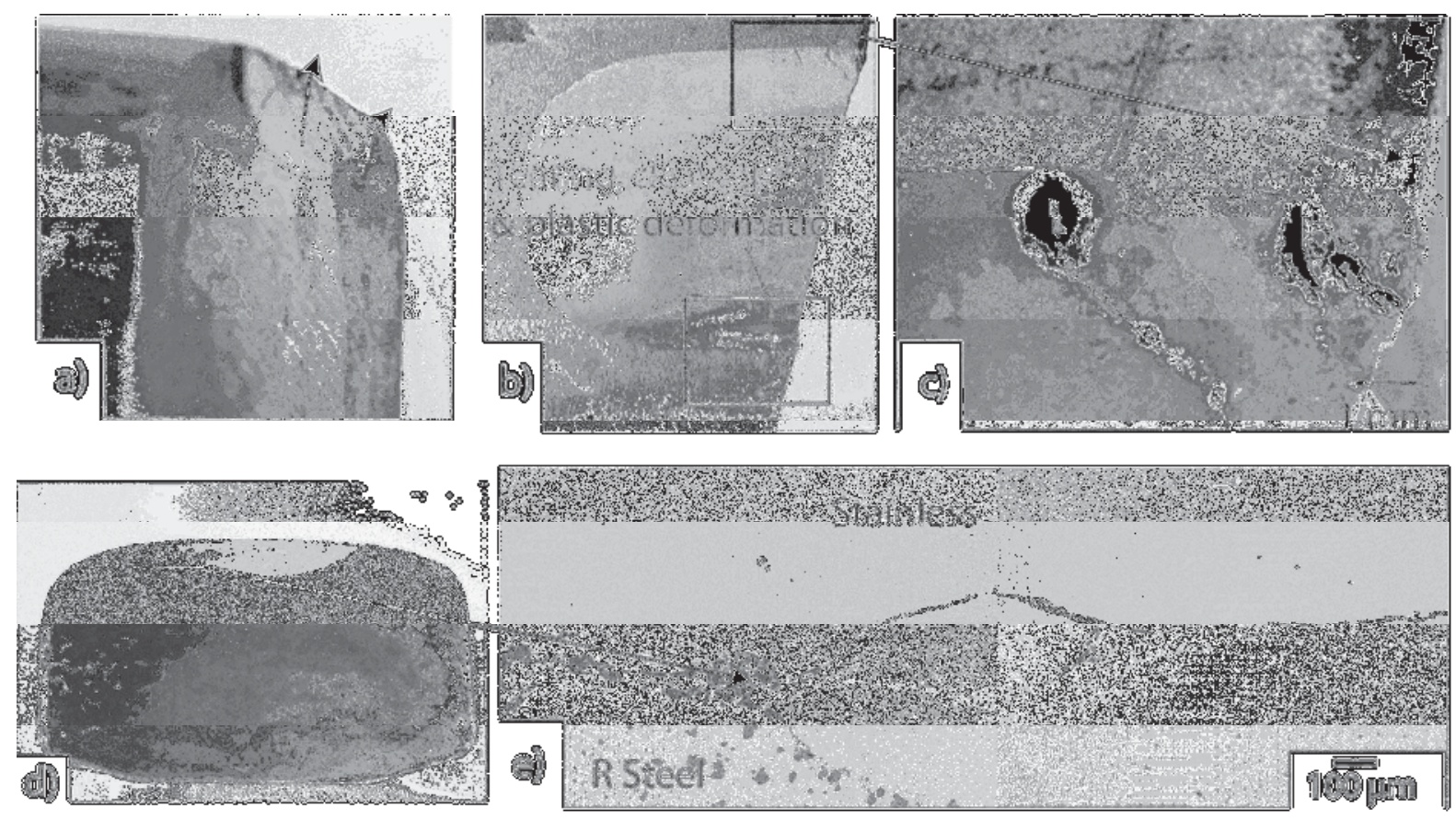

Figure 4 Laser surface coated rail. (a) rail end (b) top view, (c) SEM image of metal flow at rail end on wheel side of track (d) polished section $10 \mathrm{~mm}$ back from the rail end, (e) SEM image of void formation at interface between stainless and rail steel

\section{Hardness results}

Figure 5 Surface hardness profiles for coated and uncoated head hardened rail for the first 10 $\mathrm{mm}$ below the top surfaces and around $10 \mathrm{~mm}$ back from the rail ends.

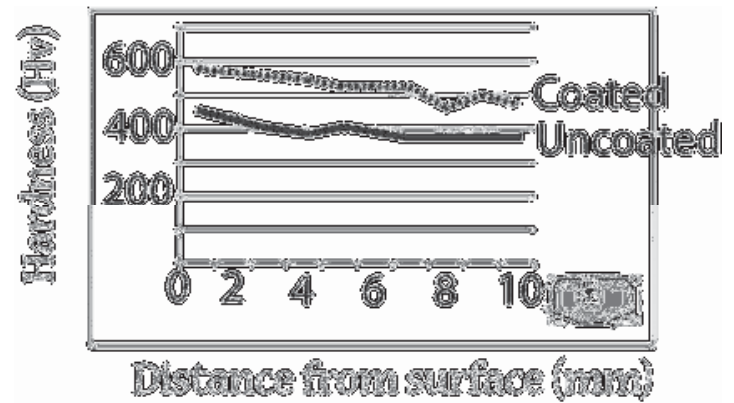

The interpretation of the latter requires data concerning complex stress and strain distributions in the railhead at and just below the rail surfaces at the rail ends. Because the rail end is free these will differ significantly from that occurring in the bulk rail. A series of experiments is currently underway using neutron diffraction to measure strain distributions in the immediate vicinity of IRJ rail ends. Further SEM-EBSD and advanced electron microscopy will be required to relate this to microstructure and properties. Alternative coating materials are also under investigation.

\section{Conclusions and Suggestions}

1. Damage to the head hardened rail IRJ ends was characterized by metal flow, RCF, and microstructural features such as spalling and cracking.

2. Compared to head hardened rail, the laser coated IRJ suffered less damage for the same heavy haul lifecycle, apparently due to the improved mechanical properties of martensitic stainless steel over medium carbon rail steel.

3. Damage to the IRJ ends of the laser coated samples was characterized by:

(i) Surface damage related to mismatches in metal flow of the two steel types, greater for the rail steel than the martensitic stainless and accentuated by the shallow angle of the interface to the rail surface and, (ii), cracking associated with the laser deposition procedure; the mismatch in thermal expansion properties of the two steel types, void formation during fabrication, defects and weakening of the heat affected zone of the base steel. 
4. Two approaches might be considered to improve the properties of the coated IRJ; redesigning the shape and position of the hard facing region to reduce surface deformation mismatches during service and selection of a weld deposit material of compatibility of thermal expansion properties.

\section{Acknowledgements}

Financial support for this project comes from the Australian CRC for Rail Innovation, Proj. R3.100, Longer life insulated rail joints. Grateful thanks to Prof M. Dhanasekar of Queensland Univ. of Technology for expert guidance and Mr B Taylor from the Australian Track and Rail Coproation for arranging the procurement of damaged IRJ samples.

\section{References}

[1] D. Peltier, C.P.L.Barkan, S.Downing, D.Socie: Measuring degradation of bonded insulated rail joints, University of Illinois at Urbana-Champaign, Urbana,IL 61801.

[2] S.W. Huang, S. Burgess, L. N. Wehrmann, D. Nolan and T. Chandra; Insulated rail joints for signalling applications, Proc. THERMEC 2006 Int. Conf. on Processing \& Manufacturing of Advanced Materials, Ed. T.Chandra et al., Trans Tech. (2006).

[3] Y. Hiroto: Development of a long life Insulated Rail Joint, Quarterly reports of the Railway Technical Research, Vol.25 (1984) p.79.

[4] C.Smalley: Preliminary study into fatigue of Insulated Rail Joints, Institute of Railway Technology at Monash University, (2009).

[5] Z. Wen, X. Jin, W. Zhang: Contact-impact stress analysis of rail joint region using the dynamic finite element method, Wear, Vol.258 (2005), p.1301.

[6] D.C. Peltier, C.P.L.Barkan: Characterizing and inspecting for progressive epoxy, Journal of the Transportation Research Record, Vol.11, (Dec 2009) p.85.

[7] J. Igwemezie, A.T. Nguyen: Anatomy of joint bar failures II, Railway Track \& Structures, Vol. 105, Issue 10, (Oct 2009) p.43.

[8] J. Igwemezie, A.T. Nguyen: Anatomy of joint bar failures III, Railway Track \& Structures, Information on http://www.rtsnds.com, (Feb 2010).

[9] V. Reddy : Modelling and Analysis of Rail Grinding \& Lubrication strategies for Controlling Rolling Contact fatigue(RCF) and Rail Wear, Master of Applied Science Thesis, Queensland University of Technology, (May, 2004).

[10] J.J.Han, M. Dhanasekar: A method for tracking internal crack propagation in railhead, International Journal of Fracture, Vol.130, (2004) p.705.

[11] Tao. Pang: Studies on Wheel/Rail contact-Impact forces at the Insulated rail Joints, Master of Engineering Thesis, Central Queensland University, Australia ( June, 2007).

[12] A.K. Himebaugh, R.H. P, D.A. Dillard: Finite element analysis of bonded insulated rail joints, International journal of Adhesion \& Adhesives, Vol. 28, (2008), p. 142.

[13] B. Talamini, D.Y. Jeong, J. Gordon, Estimation of the fatigue life of railroad joint bars, Proceedings of Joint Rail Conference \& Internal Combustion Engine Spring Technical Conference, Colorado, USA, ( March,2007).

[14] R.H. Plaut, H.L.Busch, A. Eckstein, S. Lambrecht, D.A. Dillard: Analysis of tapered, adhesively bonded, insulated rail joints, Proceedings of the Institution of Mechanical Engineers, Vol. 221 (Jun 2007) p. 195. 


\section{THERMEC 2011}

10.4028/www.scientific.net/MSF.706-709

Microstructural Characterisation of Railhead Damage in Insulated Rail Joints 10.4028/www.scientific.net/MSF.706-709.2937 